\title{
Combination of Sequential Organ Failure Assessment (SOFA) score and Charlson Comorbidity Index (CCl) could predict the severity and prognosis of candidemia more accurately than the Acute Physiology, Age, Chronic Health Evaluation II (APACHE II) score
}

Nobuhiro Asai ${ }^{1,2}$, Wataru Ohashi ${ }^{3}$, Daisuke Sakanashi ${ }^{2}$, Hiroyuki Suematsu², Hideo Kato ${ }^{2}$, Mao Hagihara ${ }^{2}$, Hiroki Watanabe ${ }^{1,2}$, Arufumi Shiota ${ }^{2}$, Yusuke Koizumi ${ }^{1,2}$, Yuka Yamagishi ${ }^{1,2}$ and Hiroshige Mikamo ${ }^{1,2^{*}}$

\begin{abstract}
Background: Candidemia has emerged as an important nosocomial infection, with a mortality rate of $30-50 \%$. It is the fourth most common nosocomial bloodstream infection (BSI) in the United States and the seventh most common nosocomial BSI in Europe and Japan. The aim of this study was to assess the performance of the Sequential Organ Failure Assessment (SOFA) score for determining the severity and prognosis of candidemia.

Methods: We performed a retrospective study of patients admitted to hospital with candidemia between September 2014 and May 2018. The severity of candidemia was evaluated using the SOFA score and the Acute Physiology, Age, Chronic Health Evaluation II (APACHE II) score. Patients' underlying diseases were assessed by the Charlson Comorbidity Index (CCI).

Results: Of 70 patients enrolled, 41 (59\%) were males, and 29 (41\%) were females. Their median age was 73 years (range: 36-93 years). The most common infection site was catheter-related bloodstream infection ( $n=36,51 \%)$.The 30-day, and inhospital mortality rates were 36 and $43 \%$, respectively.

Univariate analysis showed that SOFA score $\geq 5$, APACHE II score $\geq 13$, initial antifungal treatment with echinocandin, albumin $<2.3$, C-reactive protein $>6$, disturbance of consciousness, and $\mathrm{CCl} \geq 3$ were related with 30-day mortality. Of these 7, multivariate analysis showed that the combination of SOFA score $\geq 5$ and $\mathrm{CCl} \geq 3$ was the best independent prognostic indicator for 30-day and in-hospital mortality.

(Continued on next page)
\end{abstract}

\footnotetext{
* Correspondence: mikamo@aichi-med-u.ac.jp

'Department of Clinical Infectious Diseases, Aichi Medical University Hospital, 480-1195 1-1 Yazakokarimata, Nagakute, Aichi, Japan

${ }^{2}$ Department of Infection Control and Prevention, Aichi Medical University Hospital, Nagakute, Japan

Full list of author information is available at the end of the article
}

(c) The Author(s). 2021 Open Access This article is licensed under a Creative Commons Attribution 4.0 International License, which permits use, sharing, adaptation, distribution and reproduction in any medium or format, as long as you give appropriate credit to the original author(s) and the source, provide a link to the Creative Commons licence, and indicate if changes were made. The images or other third party material in this article are included in the article's Creative Commons licence, unless indicated otherwise in a credit line to the material. If material is not included in the article's Creative Commons licence and your intended use is not permitted by statutory regulation or exceeds the permitted use, you will need to obtain permission directly from the copyright holder. To view a copy of this licence, visit http://creativecommons.org/licenses/by/4.0/ The Creative Commons Public Domain Dedication waiver (http://creativecommons.org/publicdomain/zero/1.0/) applies to the data made available in this article, unless otherwise stated in a credit line to the data. 
(Continued from previous page)

Conclusions: The combined SOFA score and CCI was a better predictor of the 30-day mortality and in-hospital mortality than the APACHE II score alone.

Keywords: Candidemia, APACHE II, SOFA score, Bloodstream infections, Prognosis, Sequential organ failure assessment, Charlson comorbidity index, Acute physiology, age, chronic health evaluation II

\section{Background}

Candidemia has emerged as an important nosocomial infection, with a $30-50 \%$ mortality rate [1-3]. It is the fourth most common nosocomial bloodstream infection (BSI) in the United States, and the seventh most common nosocomial BSI in Europe and Japan [4-6]. Previously reported risk factors for candidemia include central venous catheterization (CVC), neutropenia, malignancy, abdominal surgery within the previous 30 days, immunosuppressant use and admission to an intensive care unit (ICU). The ubiquity of these risk factors means that most physicians may encounter patients with candidemia. However, there is no established tool or method to evaluate the severity and prognosis of patients with candidemia. The Acute Physiology, Age, Chronic Health Evaluation II (APACHE II) score has been reported to be able to predict the mortality among patients with candidemia [7]. Candidemia patients commonly have severe comorbidity which is responsible for the severity of candidemia. It is reasonable that APACHE II score is useful to predict the prognosis of candidemia as the score includes the evaluation of comorbidity [1-3]. However, in general practice, APACHE II score is very complicated to administer, and its utility in clinical practice is limited. Recently, it has been reported that quick Sequential Organ Failure Assessment (qSOFA) and Sequential Organ Failure Assessment (SOFA) scores are reliable as prognostic tools in the management of sepsis and other infections [8-10]. qSOFA and SOFA consist of 3 to 5 items and are simpler to administer than APACHE II, and are suitable for use by all physicians. Besides, we hypothesize that the Charlson Comorbidity Index (CCI) which is commonly used for the evaluation of comorbidity in general wards, would be appropriate for evaluating the patients' condition. Therefore, we conducted this retrospective study to assess whether qSOFA and SOFA scores plus CCI could predict mortality in patients with candidemia.

\section{Methods}

\section{Study design and patient selection}

In order to investigate whether SOFA score and the Charlson Comorbidity Index (CCI) could predict the severity and prognosis of patients with candidemia, we performed this retrospective study at the Aichi Medical University hospital, a 900-bed tertiary care center located in Aichi prefecture in central Japan. The study was conducted among patients hospitalized with candidiasis between September 2014 and May 2018. We included patients aged $\geq 16$ years who had hospital-acquired candidemia, which was defined as at least with one positive blood culture of Candida species in patients hospitalized for more than $48 \mathrm{~h}$, with clinical signs and symptoms of infection. Patients who did not have enough information about the disease or those we could not locate because of a transfer to other hospitals were excluded. This study was approved by the Institutional Review Board of Aichi Medical University Hospital (16-H105).

\section{Severity of candidemia}

In medical practice, the severity of the initial presentation of candidemia has been assessed using the APAC HE II score [7], qSOFA score, and SOFA score [8-10].

\section{Definition of variables}

Disseminated intravascular coagulation (DIC) was diagnosed according to the diagnostic criteria developed by the Japanese Association for Acute Medicine (JAAM DIC diagnostic criteria) [6]. An altered state of consciousness was defined as Glasgow coma scale (GCS) < 15. Neutropenia was defined as an absolute neutrophil count $<500 \times 10^{6} / \mu \mathrm{l}$.

Antifungal treatment was classified as appropriate or inappropriate depending on whether the identified pathogens were sensitive to the initially prescribed antifungal drugs.

\section{Performance status}

Patients' general conditions were evaluated by using the Eastern Cooperative Oncology Group (ECOG) performance status (PS) [11] and Karnofsky Performance Status (KPS) [12]. In medical practice, determining PS is an attempt to quantify cancer patients' general wellbeing and activities of daily living. Recently, this measurement is used to determine whether patients can receive anticancer treatment as well as a tool to evaluate conditions such as interstitial lung disease or emphysema [13-15].

\section{Evaluation of comorbidities}

We used the Charlson Comorbidity index (CCI) to evaluate the patients'comorbidities $[16,17]$. This index could forecast ten-year mortality for 22 different underlying 
Table 1 Comparison of candidemia patients among the survival and death group

\begin{tabular}{|c|c|c|c|c|}
\hline Variables & $\begin{array}{l}\text { All patients } \\
(n=70)\end{array}$ & $\begin{array}{l}\text { Death group } \\
(n=25)\end{array}$ & $\begin{array}{l}\text { Survival group } \\
(n=45)\end{array}$ & $p$-value \\
\hline Mean age (years $\pm S D$ ) & $72.4 \pm 12.1$ & $73.2 \pm 13.5$ & $71.9 \pm 11.4$ & 0.657 \\
\hline Median (range, years) & 73 (36-93) & & & \\
\hline Male gender (\%) & $40(57)$ & $11(44)$ & $29(64)$ & 0.132 \\
\hline \multicolumn{5}{|l|}{ Outcome (\%) } \\
\hline 30-days mortality & $25(36)$ & & & - \\
\hline In-hospital mortality & $30(43)$ & & & - \\
\hline \multicolumn{5}{|l|}{ Length of stay } \\
\hline Median days (range) & $67(10-418)$ & $56(11-205)$ & $72(10-418)$ & - \\
\hline Mean days $( \pm \mathrm{SD})$ & $83.1 \pm 72.4$ & $64.7 \pm 47.5$ & $93.3 \pm 82.5$ & 0.106 \\
\hline \multicolumn{5}{|l|}{ Performance status } \\
\hline ECOG-PS (mean \pm SD) & $3.3 \pm 0.8$ & $3.8 \pm 0.9$ & $3.0 \pm 0.4$ & $<0.001$ \\
\hline 0-1 (\%) & $2(3)$ & 0 & $2(4)$ & \\
\hline 2 & $11(16)$ & 0 & $11(24)$ & $<0.001$ \\
\hline 3 & $20(29)$ & $4(16)$ & $16(36)$ & $(3,4$ v.s.0-2) \\
\hline 4 & $37(52)$ & $21(84)$ & $16(36)$ & \\
\hline KPS (mean $\pm S D)$ & $42.6 \pm 17.1$ & $30.3 \pm 13.7$ & $49.3 \pm 14.7$ & $<0.001$ \\
\hline 80-100 (\%) & $2(3)$ & 0 & $2(4)$ & \\
\hline $60-70$ & $11(16)$ & 0 & $11(24)$ & $<0.001$ \\
\hline $40-50$ & $38(54)$ & $12(48)$ & $26(59)$ & $(<50$ v.s. $\geqq 50)$ \\
\hline $20-30$ & $15(21)$ & $9(36)$ & $6(13)$ & \\
\hline$\leqq 10$ & $4(6)$ & $4(16)$ & 0 & \\
\hline \multicolumn{5}{|l|}{ Site of infection (\%) } \\
\hline CRBSI & $36(52)$ & $11(44)$ & $25(56)$ & \\
\hline Others & $5(7)$ & $3(12)$ & $2(4)$ & 0.169 \\
\hline Unknown & $29(41)$ & $12(48)$ & $17(38)$ & \\
\hline \multicolumn{5}{|l|}{ Condition } \\
\hline Mental altered & $33(47)$ & $18(72)$ & $15(33)$ & 0.003 \\
\hline Shock & $15(21)$ & $7(28)$ & $8(18)$ & 0.134 \\
\hline DIC & $8(11)$ & $3(12)$ & $5(11)$ & 1.000 \\
\hline Endophthalmitis & $8 / 51(16)$ & $0 / 10(0)$ & $8 / 41(20)$ & 0.19 \\
\hline \multicolumn{5}{|l|}{ Comorbidity (\%) } \\
\hline Chronic heart failure & $9(13)$ & $9(36)$ & 0 & $<0.001$ \\
\hline Diabetes mellitus & $19(27)$ & $7(28)$ & $12(27)$ & 1.000 \\
\hline Kidney diseases & $13(19)$ & $7(28)$ & $6(13)$ & 0.199 \\
\hline Hemodialysis & $6(9)$ & $3(12)$ & $3(7)$ & 0.659 \\
\hline Hepatic diseases & $5(7)$ & $2(8)$ & $3(7)$ & 1.000 \\
\hline Malignancy & $38(54)$ & $15(60)$ & $23(51)$ & 0.617 \\
\hline Chronic respiratory disease & $6(9)$ & $3(12)$ & $3(7)$ & 0.659 \\
\hline Gastroesophageal reflex disease & $3(4)$ & $1(4)$ & $2(4)$ & 1.000 \\
\hline Dementia & $4(6)$ & $3(12)$ & $1(2)$ & 0.127 \\
\hline Cerebrovascular diseases & $13(19)$ & $4(16)$ & $9(20)$ & 0.759 \\
\hline Paralysis & $2(3)$ & $1(4)$ & $1(2)$ & 1.000 \\
\hline Collagen vascular disease & $6(9)$ & $4(16)$ & $2(4)$ & 0.177 \\
\hline
\end{tabular}


Table 1 Comparison of candidemia patients among the survival and death group (Continued)

\begin{tabular}{|c|c|c|c|c|}
\hline Variables & $\begin{array}{l}\text { All patients } \\
(n=70)\end{array}$ & $\begin{array}{l}\text { Death group } \\
(n=25)\end{array}$ & $\begin{array}{l}\text { Survival group } \\
(n=45)\end{array}$ & $p$-value \\
\hline Duration until treatment from positive blood culture within 3 days (\%) & $13(19)$ & $6(24)$ & $7(16)$ & 0.523 \\
\hline \multicolumn{5}{|l|}{ External device } \\
\hline CVC /CV port & $53(76)$ & $20(80)$ & $33(73)$ & 0.577 \\
\hline \multicolumn{5}{|l|}{ Initial antifungal treatment (\%) } \\
\hline Echinocandins & $44(63)$ & $11(44)$ & $33(73)$ & 0.021 \\
\hline L-AMB & $18(26)$ & $8(32)$ & $10(22)$ & 0.403 \\
\hline Azole & $3(4)$ & $2(8)$ & $1(2)$ & 0.289 \\
\hline Others & $5(7)$ & $4(16)$ & $1(2)$ & 0.051 \\
\hline Inappropriate initial therapy & $4(6)$ & $3(12)$ & $1(2)$ & 0.127 \\
\hline \multicolumn{5}{|l|}{ Evaluation of severity } \\
\hline APACHE II (mean \pm SD) & $12.9 \pm 4.7$ & $15.3 \pm 4.1$ & $11.6 \pm 4.5$ & 0.001 \\
\hline APACHE $\| \geqq 13(n, \%)$ & 40 & $20(80)$ & $20(44)$ & 0.005 \\
\hline SOFA score (mean \pm SD) & $3.9 \pm 3.2$ & $5.7 \pm 3.1$ & $2.9 \pm 2.9$ & $<0.001$ \\
\hline SOFA score $\geqq 5(n, \%)$ & $27(39)$ & $18(72)$ & $9(20)$ & $<0.001$ \\
\hline Charlson Comorbidity Index (mean \pm SD) & $3.5 \pm 2.7$ & $4.6 \pm 2.4$ & $3.0 \pm 2.7$ & 0.012 \\
\hline Charlson Comorbidity Index $\geqq 3(n, \%)$ & $41(59)$ & $21(84)$ & $20(44)$ & $<0.001$ \\
\hline \multicolumn{5}{|l|}{ Detection of candida spp. (n) } \\
\hline C. albicans & 27 & 12 & 15 & 0.306 \\
\hline C. parapsilosis & 20 & 6 & 14 & 0.591 \\
\hline C. glabrata & 14 & 3 & 11 & 0.35 \\
\hline C. tropicalis & 7 & 3 & 4 & 0.694 \\
\hline C. guillermondi & 5 & 1 & 4 & 0.648 \\
\hline C. dubliniensis & 1 & 1 & 0 & 0.357 \\
\hline Detection of C. albicans (v.s. non-C. albicans) & & $12(48)$ & $15(33)$ & 0.306 \\
\hline \multicolumn{5}{|l|}{ Laboratory data (Mean \pm SD) } \\
\hline White blood cell counts $(/ \mu l)$ & $10,578.1 \pm 6802$ & $12,838.8 \pm 7898$ & $9322.2 \pm 5833$ & 0.037 \\
\hline Hemoglobin (g/dl) & $9.6 \pm 1.7$ & $9.6 \pm 1.8$ & $9.6 \pm 1.7$ & 0.896 \\
\hline Hematocrit (\%) & $29.0 \pm 5.2$ & $28.8 \pm 5.4$ & $29.1 \pm 5.2$ & 0.823 \\
\hline Platelet counts $\left(\times 10^{4} / \mu l\right)$ & $19.5 \pm 11.3$ & $17.7 \pm 11.8$ & $20.5 \pm 11.1$ & 0.338 \\
\hline Total bilirubin (mg/dl) & $1.4 \pm 1.8$ & $17.7 \pm 11.8$ & $20.5 \pm 11.1$ & 0.338 \\
\hline Blood urea nitrogen (mg/dl) & $19.5 \pm 11.3$ & $1.6 \pm 1.7$ & $1.3 \pm 1.8$ & 0.514 \\
\hline Creatinine (mg/dl) & $1.4 \pm 1.7$ & $1.6 \pm 1.7$ & $1.3 \pm 1.8$ & 0.514 \\
\hline Sodium (mEq/l) & $135.5 \pm 7.4$ & $133.5 \pm 6.6$ & $136.7 \pm 7.6$ & 0.082 \\
\hline Potassium (mEq/l) & $4.1 \pm 0.6$ & $4.0 \pm 0.6$ & $4.0 \pm 0.6$ & 0.363 \\
\hline Albumin (g/dL) & $2.4 \pm 0.6$ & $2.2 \pm 0.4$ & $2.4 \pm 0.6$ & 0.059 \\
\hline C-reactive protein (mg/dL) & $7.3 \pm 5.2$ & $10.1 \pm 5.8$ & $5.7 \pm 3.9$ & $<0.001$ \\
\hline$\beta$-D-glucan (pg/mL) & $847.1 \pm 1179.9$ & $831.6 \pm 1310.5$ & $855.8 \pm 1121.8$ & 0.997 \\
\hline
\end{tabular}

*Two patients had multi-pathogens in blood culture

${ }^{*}$ CRBSI Catheter related blood stream infection, CVC Central venous catheter, DIC Disseminated intravascular coagulation, ECOG Eastern Cooperative Oncology Group, KPS Karnofsy performance status, L-AMB Liposomal amphotericin B, PS Performance status, SD Standard deviation, SOFA Sequential Organ

Failure Assessment

disease and medical conditions, including cardiac disease, AIDS, and malignancy. Each condition is assigned a score of $1,2,3$ or 6 depending on the risk of death, and the sum of these scores is used as the total score to predict mortality.

\section{Other variables}

Clinical data were collected by a review of electronic medical records. Patients' complete medical records at the time of diagnosis of candidemia were reviewed in 
$\mathbf{a}$

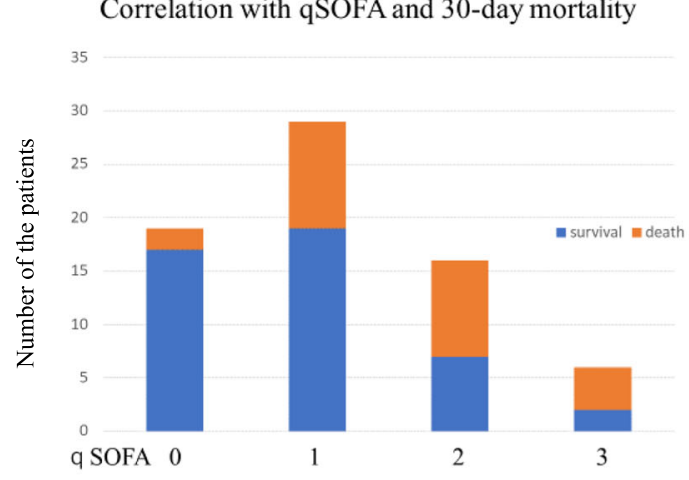

c

Correlation with APACHE II score and 30-day mortality

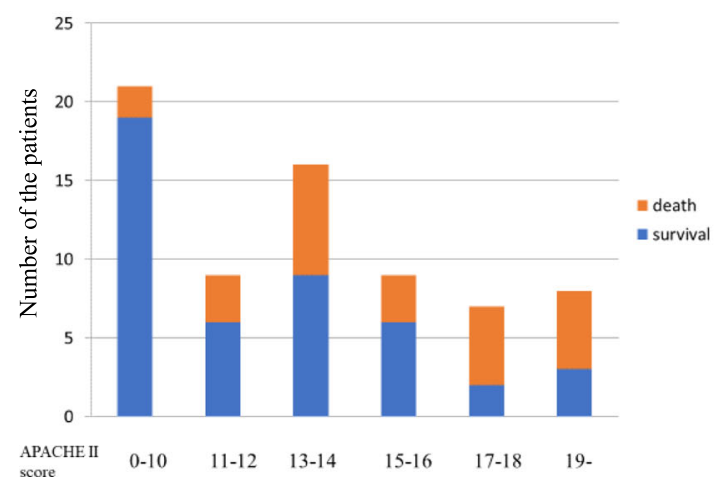

b Correlation with SOFA score and 30-day mortality

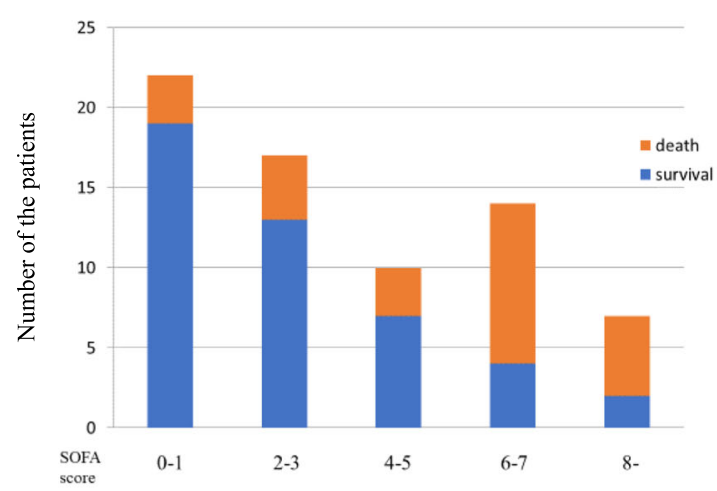

d Correlation with candida spp. and 30-day mortality

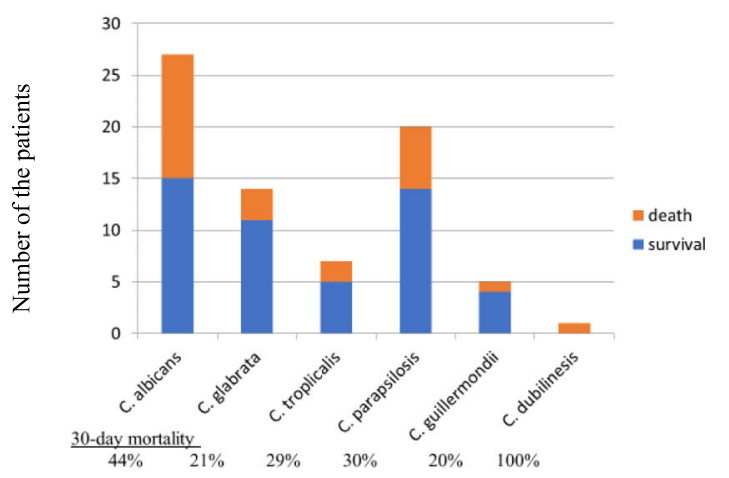

Fig. 1 Frequency distributions of: a qSOFA score; b SOFA score; c APACHE II score; and $\mathbf{d}$ Candida species

our institute. Thirty-five candidate predictors were chosen from published clinical studies as potential prognostic factors [1-6, 18-22]. Continuous variables divided into categories as follows: age $(</ \geq 70$ years); systemic blood pressure (SBP) $(</ \geq 100 \mathrm{mmHg})$; Glasgow coma scale (GCS) $(<15,15)$; white blood cells (WBC) $(<4000$, 4000-9000, > 9000 cells $/ \mu \mathrm{L})$; hemoglobin $(\mathrm{Hb})(</ \geq 11 \mathrm{~g} /$ $\mathrm{dL})$; hematocrit $(\mathrm{Ht})(<30 \%, 30-46,>46 \%)$; platelets (Plt) $(</ \geq 150,000 / \mu \mathrm{L})$; Sodium $(\mathrm{Na})(<135,135-140$, $>$ $140 \mathrm{mEq} / \mathrm{l})$; Potassium (K) $(<3.5,3.5-5.0,>5.0 \mathrm{mEq} / \mathrm{L})$; total bilirubin (TB) $(</ \geq 1.2 \mathrm{mg} / \mathrm{dL})$; C-reactive protein (CRP) $(</ \geq 6.1 \mathrm{mg} / \mathrm{dL})$; creatinine $(\mathrm{Cr})(</ \geq 1.2)$; albumin (Alb) $(</ \geq 2.3 \mathrm{~g} / \mathrm{dL}) ; \beta$-D-glucan $(</ \geq 312)$; APACHE II $(</ \geq 13)$, SOFA score $(</ \geq 5)$, CCI $(</ \geq 3)$. The cut-points for age, CRP, Alb and $\beta$-D-glucan were set to the median values, while SBP, GCS, $\mathrm{PaO}_{2} / \mathrm{FiO}_{2}$ ratio, $\mathrm{WBC}, \mathrm{Hb}$, $\mathrm{Ht}$, Plt, Na, K, TB and $\mathrm{Cr}$ were set at the value that demarcated the normal and abnormal ranges. The cutpoints for APACHE II, SOFA score and CCI were set based on the Youden Index [23].

\section{Identification of candida spp. and susceptibility testing} Candida species were identified using the VITEK-MS system (bioMérieux, Marie l'Étoile, France).
Susceptibility to amphotericin B, caspofungin, fluconazole, itraconazole, and voriconazole was detected using the AST-YS07 card of VITEK-2 (bioMérieux, Marie l'Étoile, France). The susceptibility of antifungal drugs was assessed with minimum inhibitory concentration (MIC) testing according to the guidelines of the Clinical and Laboratory Standards Institute (CLSI) [24, 25]. MIC values were interpreted according to species-specific clinical breakpoints as established by CLSI for caspofungin (CPFG), fluconazole (FLCZ), itraconazole (ITCZ) (only for C. albicans), and voriconazole (VRCZ) [24]. Susceptibility to amphotericin B (AMB) and liposomal amphotericin $B$ (L-AMB) were interpreted according to species-specific clinical breakpoints as established by European Committee on Antimicrobial Susceptibility Testing (EUCAST) [25].

\section{Statistical analyses}

The data for categorical variables were reported as percentages, and continuous variables were reported as the mean \pm the standard deviation (SD), or the median with the interquartile range (IQR). Chi-square tests or Fisher's exact tests (two-tailed) were used to compare categorical variables, and unpaired Student's t-tests or 


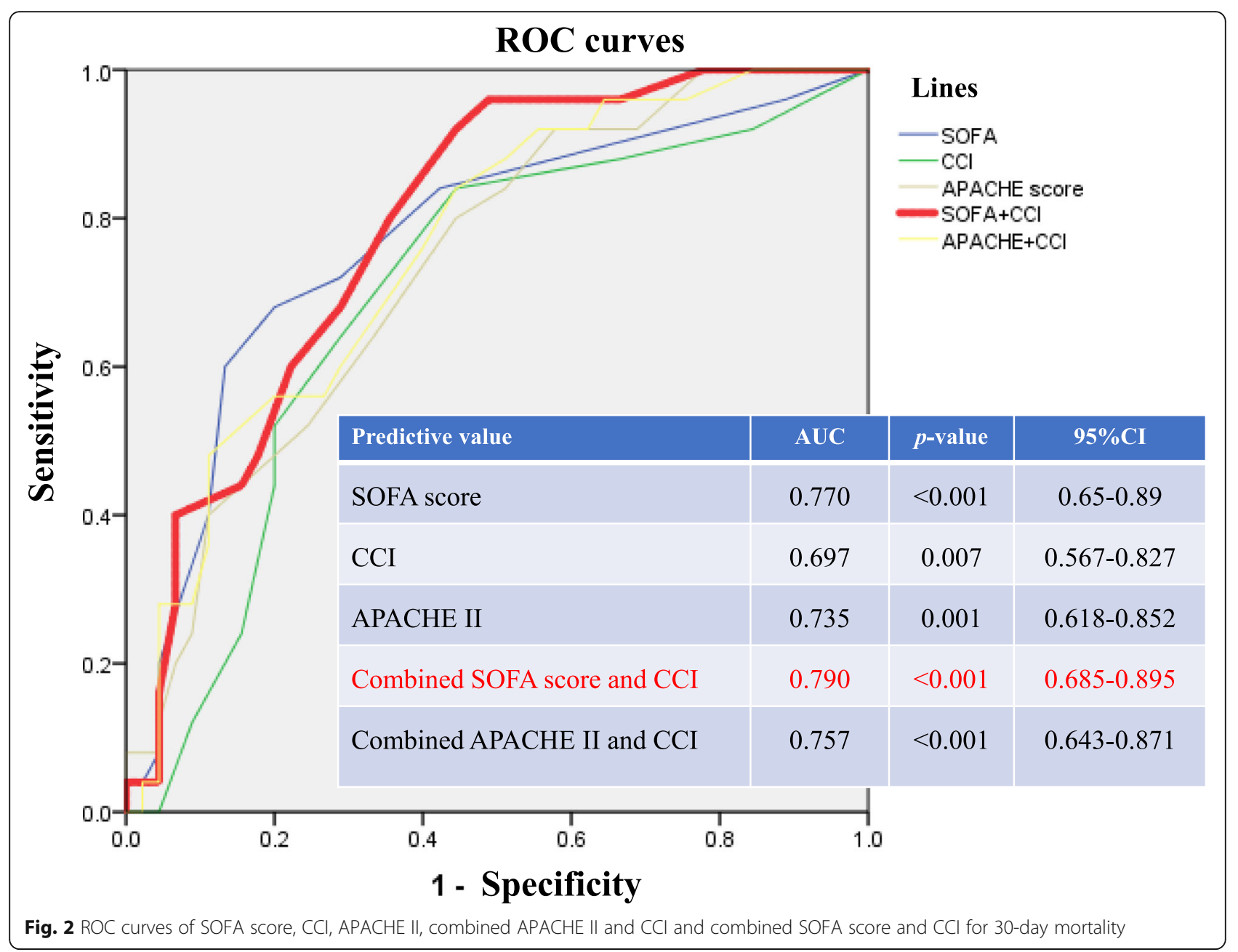

Mann-Whitney U-test were used to compare continuous variables. Logistic regression analysis was used to identify independent risk factors associated with 30-day or in-hospital mortality. Variables with $p \leq 0.10$ on univariate analyses were entered into the multivariable model. The Hosmer-Lemeshow test was performed to assess the calibration of the model. Receiver-operating characteristic (ROC) curves were evaluated for the predictive values for 30-day or in-hospital mortality. Statistical analyses were performed using SPSS Version 23 for Windows (SPSS Inc., Chicago, IL, USA). A $p$-value $<0.05$ was considered statistically significant.

\section{Results}

\section{Incidence of candidemia}

During the study period (941,990 patient-days), the incidence of candidemia was 7.4/100,000 persons. Candida spp. was the fourth most common pathogen among patients with bloodstream infections in our institute, after coagulase-negative Staphylococcus, Escherichia coli, and Staphylococcus aureus, accounting for $7 \%$ of positive blood cultures.

\section{Demographic data}

The demographic data and clinical characteristics of the patients, clinical outcomes, pathogens isolated were summarized in Table 1. A total of 70 patients with candidemia were enrolled in this study, of whom 41 (59\%) were males and 29 (41\%) were females. Their median age was 73 years (range $36-93$ years).

The patients had a 30-day mortality of 36\%, and an inhospital mortality of $43 \%$. Six of the 10 patients who received an antifungal treatment based on a positive blood culture, died. Of the 68 patients, 27 (40\%) received antifungal treatment within $24 \mathrm{~h}$ from the onset. The difference in the time to starting antifungal treatment did not differ significantly between those who survived, and those who died ( $45.6 \mathrm{~h}$ vs $36 \mathrm{~h}, p=0.4$ ).

\section{Microbiological data and antifungal drug selection Detection of Candida spp.}

C. albicans was the most common of the Candida species identified, accounting for $39 \%$ of the cases, followed by C. parapsilosis (28\%), C. glabrata (20\%), C. tropicalis (10\%) and others (9\%). The 30-day mortality according 


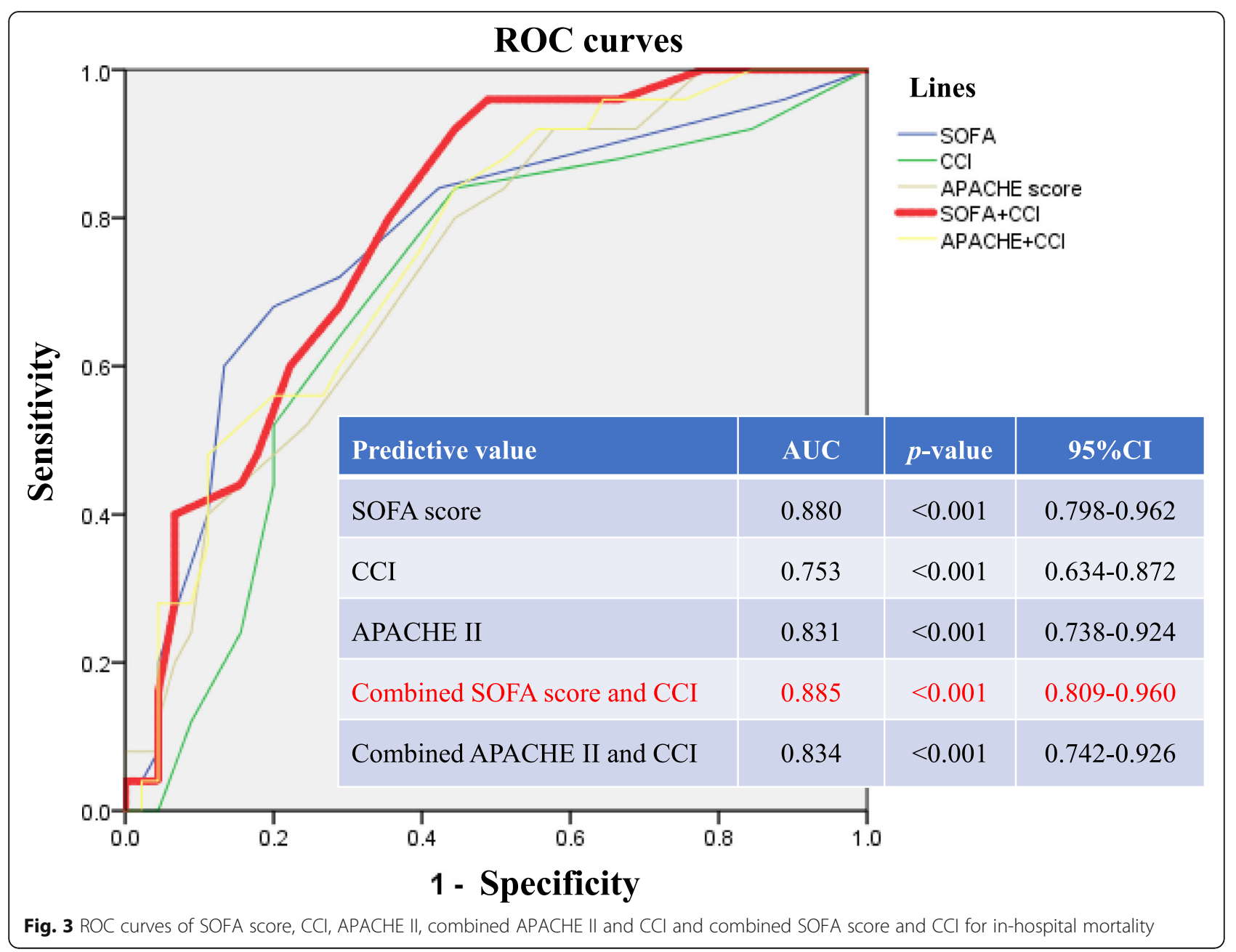

to species was highest in patients with Patients with $C$. albicans candidemia had the highest mortality (44\%). $C$. albicans candidemia (vs. non-C. albicans) was not associated with an increased 30-day mortality (12/25 [48\%] vs. $15 / 47$ [32\%], $p=0.31$ ), but was associated with significantly higher in-hospital mortality (18/33 [55\%] vs. 9/37 [24\%], $p=0.01$ ).

The most frequently used initial antifungal treatments were echinocandin (63\%), and L-AMB (26\%). All candida isolates were susceptible to initial antifungal agents based on CLSI and EUCAST breakpoints. Of the 70 patients, $74 \%$ received antifungal treatment within 3 days of the onset, which reflects the period taken for fungus to grow from the blood cultures., and only three patients (4\%) did not receive antifungal treatment.

\section{Relationship between qSOFA, SOFA, APACHE II eastern cooperative oncology group performance status and Karnofsky performance status}

The SOFA, APACHE II score and ECOG-PS were higher patients with $\mathrm{qSOFA} \geq 2$ than in those with
qSOFA $<2$. KPS was lower in patients with qSOFA $\geq 2$ than in those with qSOFA $<2$ (Table S1).

\section{Associations between qSOFA, SOFA score and 30-day mortality}

The associations between qSOFA, SOFA, APACHE II score, Candida spp. and 30-day mortality among are shown in Fig. 1. Higher qSOFA and SOFA scores were associated with a higher 30-day mortality. The 30-day mortality of Candida albicans was the highest among these patients.

Relationship between removal of central venous catheters and outcomes

External devices such as CVCs or CV ports were removed in 43 of the $53(81 \%)$ patients. CVCs or CV ports were removed within $24 \mathrm{~h}$ from the onset in 29 of the 43 patients (67\%). In 37 of the 43 patients (86\%), CVCs or $\mathrm{CV}$ ports were removed within 3 days of the onset of candidemia. Seven of the 53 patients (13\%) did not have their CVCs or CV ports removed. Not removing CVCs or CV ports was a poor prognostic factor (OR 12.5, 95\% 
Table 2 Prognostic accuracy of SOFA score and APACHE II among candidemia patients for 30-day mortality.

\begin{tabular}{|c|c|c|c|c|c|}
\hline Predictive value & Sensitivity (\%) & Specificity (\%) & PPV (\%) & NPV (\%) & YI \\
\hline SOFA score $\geqq 5$ & 68 & 80 & 65 & 82 & 0.48 \\
\hline SOFA score $\geqq 6$ & 60 & 87 & 71 & 80 & 0.47 \\
\hline APACHE $\| \geqq 13$ & 80 & 56 & 50 & 83 & 0.36 \\
\hline APACHE $\| \geqq 15$ & 52 & 76 & 54 & 74 & 0.28 \\
\hline
\end{tabular}

*SOFA Sequential Organ Failure Assessment, YI Youden index

CI: 1.5-107.6, $p=0.01)$. However, removing CVCs or CV ports within $24 \mathrm{~h}$ of the onset did not have an observable effect on mortality (OR: $0.8,95 \% \mathrm{CI}: 0.3-2.3, p=0.79$ ).

In terms of the patients with cancer, there were no differences of ECOG-PS and KPS between the patients with and without CVCs or CV ports (data not shown). As for the 28 cancer patients with CVCs or CV ports, not removing CVCs or CV port was a poor prognostic factor (OR 7.4, 95\% CI: $1.5-$ 152.3, $p=0.008)$. Removing CVCs or CV ports within $24 \mathrm{~h}$ of the onset was not a poor prognostic factor (OR 0.6, 95\% CI: $0.1-2.5, p=0.445)$.

\section{Receiver-operating characteristic (ROC) curves of predictive values for 30-day or in-hospital mortality} (Figs. 2 and 3)

With respect to the diagnostic value of predictive values for 30day and in-hospital mortality among candidemia patients, the area under the ROC curve for SOFA score, CCI, APACHE II score, combined SOFA score with CCI and combined APAC HE II score with CCI were 0.77 (95\% CI:0.65-0.89, $p<0.001$ ) and 0.88 (95\% CI:0.798-0.962, $p<0.001$ ), 0.697 (95\%CI:0.5670.827, $p=0.007$ ) and 0.753 (95\%CI:0.634-0.872, $p<0.001$ ), 0.735 (95\% CI:0.618-0.852, $p=0.001$ ) and 0.831 (95\% CI:0.738-0.924, $p<0.001), 0.79$ (95\% CI:0.685-0.895, $p<0.001)$ and 0.885 (95\% CI:0.809-0.96, $p<0.001$ ) and 0.757 (95\%CI: 0.643-0.871, $p<$ $0.001)$ and 0.834 (95\% CI: $0.742-0.926, p<0.001)$, respectively.

Prognostic accuracy of SOFA and APACHE II score for 30day mortality

Table 2 shows the prognostic accuracy of SOFA and APACHE II for predicting 30-day mortality. The cut- point for the SOFA score was 5. and was selected based on the Youden Index.

\section{Analysis of prognostic factors}

The prognostic factors for 30-day mortality are shown in Table 3. Seven of 35 parameters (Table S2) were found to be associated with 30-day mortality in the univariate analysis. These were: SOFA score $\geq 5$, APACHE II score $\geq 13$, initial antifungal treatment with echinocandin, albumin $<2.3$, C-reactive protein $>6$, disturbance of consciousness, and CCI $\geq 3$. The Hosmer Lemeshow statistic suggested a good fit $\left(\chi^{2}=11.4, p=0.184\right)$ in the cohort study.

Of these seven parameters, logistic regression analysis showed that the combination of SOFA score $\geq 5$ and CCI $\geq 3$ were independent prognostic factors for 30-day mortality and in-hospital mortality (Table 4).

\section{Discussion}

In contrast to the complicated APACHE II scoring system, which consists of ASP points, age and immunocompromised state, both the SOFA score and CCI are simple to calculate. SOFA is a tool for evaluating the severity of failure of organs such as the kidney or the liver [26]. In addition, while platelet count is included in SOFA score, it is not included in APACHE II. This difference might contribute to the more precise evaluation of patients' conditions by SOFA compared to APACHE II in seriously ill patients with conditions such as disseminated intravascular coagulation or multiple organ failure. In this study, 23 of the 70 patients were diagnosed as having candidemia in ICU, while the remaining

Table 3 Univariate and multivariate analyses among candidemia patients for 30-day death

\begin{tabular}{|c|c|c|c|c|c|c|}
\hline \multirow[t]{2}{*}{ Variables } & \multicolumn{3}{|c|}{ Univariate analysis } & \multicolumn{3}{|c|}{ Multivariate analysis } \\
\hline & $\overline{\mathrm{OR}}$ & $95 \% \mathrm{Cl}$ & $\overline{p \text {-value }}$ & $\overline{\mathrm{OR}}$ & $95 \% \mathrm{Cl}$ & $p$-value \\
\hline SOFA score $\geqq 5$ & 10.3 & $3.3-32.1$ & $<0.001$ & 6.5 & $1.6-26.4$ & 0.008 \\
\hline APACHE $\| \geqq 13$ & 5.0 & $1.6-15.7$ & 0.008 & & & \\
\hline Echinocandin use as initial treatment & 0.3 & $0.1-0.8$ & 0.021 & & & \\
\hline $\mathrm{Alb}<2.3 \mathrm{~g} / \mathrm{dl}$ & 2.6 & $0.9-7.0$ & 0.08 & & & \\
\hline $\mathrm{CRP} \geqq 6.1 \mathrm{mg} / \mathrm{dl}$ & 2.7 & $1.0-7.3$ & 0.081 & & & \\
\hline Disturbance of consciousness & 5.1 & $1.8-15.0$ & 0.03 & & & \\
\hline $\mathrm{CCl} \geqq 3$ & 6.6 & $1.9-22.2$ & 0.002 & 4.9 & $1.1-23.2$ & 0.043 \\
\hline
\end{tabular}

*Alb Albumin, $\mathrm{CCl}$ the Charlson Comorbidity Index, Cl Confidential interval, CRP C-reactive protein 
Table 4 Univariate and multivariate analyses among candidemia patients for in-hospital death

\begin{tabular}{|c|c|c|c|c|c|c|}
\hline \multirow[t]{2}{*}{ Variables } & \multicolumn{3}{|c|}{ Univariate analysis } & \multicolumn{3}{|c|}{ Multivariate analysis } \\
\hline & OR & $95 \% \mathrm{Cl}$ & $p$-value & OR & $95 \% \mathrm{Cl}$ & $p$-value \\
\hline SOFA score $\geqq 5$ & 19.0 & $5.3-68.0$ & $<0.001$ & 26.4 & $3.4-202.4$ & 0.002 \\
\hline APACHE $\| \geqq 13$ & 8.3 & $2.7-25.3$ & $<0.001$ & & & \\
\hline Echinocandin use as initial treatment & 0.4 & $0.2-1.1$ & 0.084 & & & \\
\hline $\mathrm{Alb}<2.3 \mathrm{~g} / \mathrm{dl}$ & 4.8 & $1.7-13.4$ & 0.08 & & & \\
\hline Disturbance of consciousness & 8.3 & $2.8-24.3$ & $<0.001$ & & & \\
\hline $\mathrm{CCl} \geqq 3$ & 10.3 & $3.2-33.2$ & $<0.001$ & 15.6 & $2.1-116.0$ & 0.007 \\
\hline
\end{tabular}

*Alb Albumin, CCl the Charlson Comorbidity Index, Cl Confidential interval, CRP C-reactive protein

${ }^{*} \mathrm{C}$ CRP is not a poor prognostic factor among candidemia patients for in-hospital death

47 patients were diagnosed in a general ward. Table S1 showed that the patients with $\mathrm{qSOFA} \geqq 2$ could reflect the disease severity of SOFA score and APACHE II score. In a general ward, patients' condition should be evaluated by qSOFA [27] ( $\gamma=0.505$ with Spearman's rank correlation test). The results showed the validity of qSOFA among candidemia patients in a general ward. The severity and prognosis of candidemia could be evaluated by SOFA score more reliably than by APACHE II. $\mathrm{CCI}$ is a useful tool for evaluating comorbid conditions in patients with underlying diseases $[13,14]$. Furthermore, the outcome of candidemia can be affected by patients' general condition and underlying diseases such as malignancy. Thus, it is reasonable that combined SOFA score and CCI could more precisely predict the severity and prognosis of patients with candidemia.

Removal of CVCs is considered to be a standard procedure among patients with candidemia [27, 28]. Although it has been reported that removing CVCs within $24 \mathrm{~h}$ of the onset of candidemia is associated with a reduced mortality rate [29], our study results did not confirm this finding. These discrepancies may be attributable to the lack of uniformity of variables and differences in both previous studies and ours. We found that patients whose CVCs were removed, showed better PSs and had lower SOFA scores than those whose CVCs were not removed (Table 5).

We can assume that physicians tended to remove CVCs of patients in good general condition, whose life expectancy is considered favorable. Conversely, physicians might be hesitant to remove CVCs of patients with poor general condition.

Candidemia is almost always primarily of gastrointestinal origin in patients with cancer who have severe neutropenia and mucositis, and removal of CVCs is less likely to have an impact on the outcome in this setting. However, we believe that removal of CVCs is appropriate in the treatment of patients with candidemia considering that CVCs are foreign bodies.

On insertion of CVCs, physicians should take into account the ease and safety of CVC removal when candidemia is suspected, and select catheter device. Peripherally inserted central venous catheters could be removed easier and safer than $\mathrm{CV}$ port.

This study has several limitations. Firstly, it is a retrospective study with a relatively low sample size. Thus, there might be a bias in the data selection and analysis. Secondly, we enrolled only patients with candidemia diagnosed by a blood culture. Generally, $50 \%$ of individuals with candidemia have negative blood cultures. Thus, the patients in our study may not have been representative of all individuals with candidemia.

\section{Conclusions}

Combined SOFA score and CCI could possibly be a more accurate predictor of severity and prognosis among patients with candidemia than the APACHE II score for 30-day, or in-hospital death.

Table 5 Comparison between score values of candidemia patients who removed or did not remove CVCs

\begin{tabular}{llll}
\hline $\begin{array}{l}\text { Score values } \\
\text { (Mean } \pm \text { SD) }\end{array}$ & $\begin{array}{l}\text { Removal of CVCs } \\
(\boldsymbol{n}=\mathbf{4 3})\end{array}$ & Non-removal of CVCs $(\boldsymbol{n}=\mathbf{1 0})$ & $\boldsymbol{p}$-value \\
\hline ECOG-PS & $3.1 \pm 0.9$ & $3.8 \pm 0.4$ & $0.019 \mathbf{9}$ \\
KPS & $49.1 \pm 16$. & $27 \pm 16.4$ & $<0.001$ \\
SOFA SCOre & $3.4 \pm 3.4$ & $6.3 \pm 2.6$ & 0.021 \\
APACHE II & $11.5 \pm 4.9$ & $16.1 \pm 4.4$ & 0.008 \\
CCI & $3.2 \pm 2.8$ & $5.6 \pm 2.3$ & 0.014 \\
\hline
\end{tabular}

${ }^{*} \mathrm{CCl}$ the Charlson Comorbidity Index, CVC Central venous catheter, ECOG Eastern Cooperative Oncology Group, KPS Karnofsy performance status, PS Performance status, SD Standard deviation, SOFA Sequential Organ Failure Assessment 


\section{Supplementary Information}

The online version contains supplementary material available at https://doi. org/10.1186/s12879-020-05719-8.

Additional file 1: Table S1. Comparison with predictive values among candidemia patients with $\mathrm{qSOFA} \geqq 2$ and those with $<2$.

Additional file 2: Table S2. Prognostic factor for 30-day mortality by an univariate analysis.

\section{Abbreviations}

AMB: Amphotericin B; APACHE II: Acute Physiology, Age, Chronic Health Evaluation II; AUROC: Area under the receiver-operating characteristic curve; Alb: Albumin; BSI: Blood stream infection; CCl: Charlson Comorbidity Index; CLSI: Clinical and Laboratory Standards Institute; CPFG: Caspofungin; CRP: C reactive protein; CVC: Central venous catheter; Cr: Creatinine; DIC: Disseminated intravascular coagulation; ECOG: Eastern Cooperative Oncology Group; EUCAST: European Committee on Antimicrobial Susceptibility Testing; FLCZ: Fluconazole; GCS: Glasgow coma scale; Hb: Hemoglobin; Ht: Hematocrit; ICU: Intensive care unit; IQR: Interquartile range; ITCZ: Itraconazole; JAAM: Japanese Association for Acute Medicine; K: Potassium; KPS: Karnofsky Performance Status; L-AMB: Liposomal amphotericin B; MIC: Minimum inhibitory concentration; Na: Sodium; PS: Performance status; Plt: Platelets; SBP: Systemic blood pressure; SD: Standard deviation; SOFA: Sequential Organ Failure Assessment; TB: Total bilirubin; VRCZ: Voriconazole; WBC: White blood cells; qSOFA: Quick Sequential Organ Failure Assessment

\section{Acknowledgments}

We are grateful for the diligent and thorough critical reading of ou manuscript by Dr. Yoshihiro Ohkuni, Chief Physician, Taiyo and Mr. John Wocher, Executive Vice President and Director, International Affairs/ International Patient Services, Kameda Medical Center, Japan.

\section{Authors' contributions}

NA, AS, HK, MH, HW, YK, YY, HM carried out the clinical follow up. NA draft the manuscript. NA, AY, HW, NN, DS and HS performed microbial testing and $\mathrm{NA}, \mathrm{HW}, \mathrm{YK}, \mathrm{YY}, \mathrm{HM}$ performed laboratory analysis. $\mathrm{HK}, \mathrm{AS}$ and $\mathrm{MH}$ supervised the antibiotic and antiviral therapy. NA and WO performed the statistical analysis. All authors read and approved the final manuscript.

\section{Funding}

This study is partially supported by Japan Agency for Medical Research and Development (AMED) JP20fk0108094.

\section{Availability of data and materials}

All data generated or analyzed during this study are included in this published article and are found in result session and supplementary information (Additional files 1 and 2).

\section{Ethics approval and consent to participate}

The study was conducted in accordance with the ethical principles of the Declaration of Helsinki and the local regulations, and was approved by the Institutional Review Board of Aichi Medical University Hospital. Informed consent was waived, since only leftover materials, otherwise discarded, were used, and no additional intervention or change in treatment plan was implemented.

\section{Consent for publication}

Not applicable.

\section{Competing interests}

None declared.

\section{Author details}

${ }^{1}$ Department of Clinical Infectious Diseases, Aichi Medical University Hospital, 480-1195 1-1 Yazakokarimata, Nagakute, Aichi, Japan. ²Department of Infection Control and Prevention, Aichi Medical University Hospital, Nagakute, Japan. ${ }^{3}$ Division of Biostatistics, Clinical Research Center, Aichi Medical University Hospital, Nagakute, Japan.
Received: 3 November 2019 Accepted: 18 December 2020

Published online: 15 January 2021

\section{References}

1. Zaoutis TE, Argon J, Chu J, Berlin JA, Walsh TJ, Feudtner C. The epidemiology and attributable outcomes of candidemia in adults and children hospitalized in the United States: a propensity analysis. Clin Infect Dis. 2005;41:1232-9. https://doi.org/10.1086/496922.

2. Horn DL, Neofytos D, Anaissie EJ, Fishman JA, Steinbach WJ, Olyaei AJ, et al. Epidemiology and outcomes of candidemia in 2019 patients: data from the prospective antifungal therapy alliance registry. Clin Infect Dis. 2009;48: 1695-703. https://doi.org/10.1086/599039.

3. Ostrosky-Zeichner L, Kullberg BJ, Bow EJ, Hadley S, Leon C, Nucci M, et al. Early treatment of candidemia in adults: a review. Med Mycol. 2011;49:11320. https://doi.org/10.3109/13693786.2010.512300.

4. Wisplinghoff $H$, Bischoff $T$, Tallent SM, Seifert $H$, Wenzel RP, Edmond MB. Nosocomial bloodstream infections in US hospitals: analysis of 24,179 cases from a prospective nationwide surveillance study. Clin Infect Dis. 2004;39: 309-17. https://doi.org/10.1086/421946.

5. Lamagni TL, Evans BG, Shigematsu M, Johnson EM. Emerging trends in the epidemiology of invasive mycoses in England and Wales (1990-9). Epidemiol Infect. 2001;126:397-414. https://doi.org/10.1017/ s0950268801005507.

6. Gando S, Iba T, Equchi Y, Ohtomo Y, Okamoto K, Koseki K, et al. A multicenter, prospective validation of disseminated intravascular coagulation diagnostic criteria for critically ill patients: comparing current criteria. Crit Care Med. 2006;34:625-31. https://doi.org/10.1097/01.ccm. 0000202209.42491.38.

7. Chang RW, Jacobs S, Lee B. Predicting outcome among intensive care unit patients using computerised trend analysis of daily Apache II scores corrected for organ system failure. Intensive Care Med. 1988;14:558-66. https://doi.org/10.1007/bf00263530.

8. Ranzani OT, Prina E, Menéndez R, Ceccato A, Cilloniz C, Méndez R, et al. New Sepsis definition (Sepsis-3) and community-acquired pneumonia mortality: a validation and clinical decision-making study. Am J Respir Crit Care Med. 2017;196:1287-97. https://doi.org/10.1164/rccm.201611-2262OC.

9. Asai N, Watanabe H, Shiota A, Kato H, Sakanashi D, Hagihara M, et al. Could qSOFA and SOFA score be correctly estimating the severity of healthcareassociated pneumonia? J Infect Chemother. 2018;24:228-31. https://doi.org/ 10.1016/j.jiac.2017.10.004

10. Fukushima H, Kobayashi M, Kawano K, Morimoto S. Performance of quick sequential (Sepsis related) and sequential (Sepsis related) organ failure assessment to predict mortality in patients with acute pyelonephritis associated with upper urinary tract calculi. J Urol. 2018;199:1526-33. https:// doi.org/10.1016/j.juro.2017.12.052

11. Oken MM, Creech RH, Tormey DC, Horton J, Davis TE, McFadden ET, et al. Toxicity and response criteria of the eastern cooperative oncology group. Am J Clin Onco. 1982;5:649-55. https://doi.org/10.1097/00000421198212000-00014

12. de Kock I, Mirhosseini M, Lau F, Thai V, Downing M, Quan H, et al. Conversion of Karnofsky performance status (KPS) and eastern cooperative oncology group performance status (ECOG) to palliative performance scale (PPS), and the interchangeability of PPS and KPS in prognostic tools. J Palliat Care. 2013;29:163-9. https://doi.org/10.1177/082585971302900305.

13. Matsunuma R, Kase K, Asai N, Watanabe S, Waseda Y, Kaneko N, Aoshima M, et al. Drainage using chest tubes smaller than 20 French is suitable for patients with thoracic empyema. Int J Respir Pulm Med. 2016;3:058.

14. Asai N, Katsuda E, Hamanaka R, Kosaka K, Matsubara A, Nishimura M, et al. The ATS/ERS/JRS/ALAT statement "IPF by HRCT" could predict acute exacerbation of interstitial lung disease in non-small cell lung cancer. Tumori. 2017;103:60-5.

15. Asai N, Motojima S, Ohkuni Y, Matsunuma R, Iwasaki T, Nakashima K, Sogawa K, Nakashita T, Kaneko N. Clinical manifestations and prognostic factors of pneumocystis jirovecii pneumonia without HIV. Chemotherapy. 2017;62:343-9.

16. Charlson ME, Pompei $P$, Ales $K L$, Mackenzie CR. A new method of classifying prognostic comorbidity in longitudinal studies: development and validation. J Chron Dis. 1987;40:373-83. https://doi.org/10.1016/0021-9681(87)90171-8.

17. de Groot V, Beckerman H, Lankhorst GJ, Bouter LM. How to measure comorbidity: a critical review of available methods. J Clin Epidemiol. 2003; 56:221-9. https://doi.org/10.1016/j.jclinepi.2003.09.002. 
18. Kullberg BJ, Arendrup MC. Invasive Candidiasis. N Engl J Med. 2015;373: 1445-56. https://doi.org/10.1056/NEJMc1514201.

19. Andes DR, Safdar N, Baddley JW, Playford G, Reboli AC, Rex JH, et al. Impact of treatment strategy on outcomes in patients with candidemia and other forms of invasive candidiasis: a patient-level quantitative review of randomized trials. Clin Infect Dis. 2012;54:1110-22. https://doi.org/10.1093/ $\mathrm{cid} / \mathrm{cis} 021$.

20. Kollef M, Micek S, Hampton N, Doherty JA, Kumar A. Septic shock attributed to Candida infection: importance of empiric therapy and source control. Clin Infect Dis. 2012;54:1739-46. https://doi.org/10.1093/cid/cis305.

21. Eschenauer GA, Carver PL, Lin SW, Klinker KP, Chen YC, Potoski BA, et al, Fluconazole versus an echinocandin for Candida glabrata fungaemia: a retrospective cohort study. J Antimicrob Chemother. 2013;68:922-6. https:// doi.org/10.1093/jac/dks482.

22. Barchiesi F, Orsetti E, Mazzanti S, Trave F, Salvi A, Nitti C, et al. Candidemia in the elderly: what does it change? PLoS One. 2017;12:e0176576. https:// doi.org/10.1371/journal.pone.0176576.

23. Yin J, Tian L. Joint confidence region estimation for area under ROC curve and Youden index. Stat Med. 2014;33:985-1000.

24. Clinical and Laboratory Standards Institute (CLSI). Performance Standards for Antifungal Susceptibility Testing of Yeasts. CLSI supplement M60. 1st ed, PA: clinical and laboratory standards institute; 2017.

25. European Committee on Antibiotic Susceptibility Testing (EUCAST) Antifungal Clinical Breakpoint. (http://www.eucast.org/fileadmin/src/media/ PDFs/EUCAST_files/AFST/Clinical_breakpoints/Antifungal_breakpoints_v_9. 0_180212.pdf).

26. Raith EP, Udy AA, Bailey M, McGloughlin S, Maclsaac C, Bellomo R, et al. Australian and new Zealand Intensive Care Society (ANZICS) Centre for Outcomes and Resource Evaluation (CORE). Prognostic accuracy of the SOFA score, SIRS criteria, and qSOFA score for in-hospital mortality among adults with suspected infection admitted to the intensive care unit. JAMA. 2017;317:290-300. https://doi.org/10.1001/jama.2016.20328. Accessed 1 Nov 2019.

27. Rex JH, Walsh TJ, Sobel JD, Filler SG, Pappas PG, Dismukes WE, et al. Practice guidelines for the treatment of candidiasis. Infectious Diseases Society of America. Clin Infect Dis. 2000;30:662-78. https://doi.org/10.1086/313749.

28. Mermel LA, Farr BM, Sherertz RJ, Raad II, O'Grady N, Harris JS, et al. Guidelines for the management of intravascular catheter-related infections. Clin Infect Dis. 2001;32:1249-72. https://doi.org/10.1086/320001.

29. Nucci M, Anaissie E. Should vascular catheters be removed from all patients with candidemia? An evidence-based review. Clin Infect Dis. 2002;34:591-9. https://doi.org/10.1086/338714.

\section{Publisher's Note}

Springer Nature remains neutral with regard to jurisdictional claims in published maps and institutional affiliations.

Ready to submit your research? Choose BMC and benefit from:

- fast, convenient online submission

- thorough peer review by experienced researchers in your field

- rapid publication on acceptance

- support for research data, including large and complex data types

- gold Open Access which fosters wider collaboration and increased citations

- maximum visibility for your research: over $100 \mathrm{M}$ website views per year

At $\mathrm{BMC}$, research is always in progress.

Learn more biomedcentral.com/submissions 